Revue bibliographique pour le domaine irano-aryen

\title{
Michele Minardi. « Elite, Wine Consumption and Status Symbols in Ancient Chorasmia »
}

Johanna Lhuillier

\section{(2) OpenEdition \\ 12 Journals}

\section{Édition électronique}

URL : http://journals.openedition.org/abstractairanica/44694

DOI : 10.4000/abstractairanica.44694

ISBN : 1961-960X

ISSN : 1961-960X

Éditeur :

CNRS (UMR 7528 Mondes iraniens et indiens), Éditions de l'IFRI

Référence électronique

Johanna Lhuillier, « Michele Minardi. «Elite, Wine Consumption and Status Symbols in Ancient Chorasmia » », Abstracta Iranica [En ligne], Volume 37-38-39 | 2018, document 6, mis en ligne le 30 décembre 2018, consulté le 28 septembre 2020. URL : http://journals.openedition.org/ abstractairanica/44694; DOI : https://doi.org/10.4000/abstractairanica.44694

Ce document a été généré automatiquement le 28 septembre 2020.

Tous droits réservés 


\section{Michele Minardi. « Elite, Wine Consumption and Status Symbols in Ancient Chorasmia »}

Johanna Lhuillier

\section{RÉFÉRENCE}

Michele Minardi. « Elite, Wine Consumption and Status Symbols in Ancient Chorasmia ", Ancient Civilizations from Scythia to Siberia 22, 2016, p. 262-294.

1 L'auteur présente deux objets exceptionnels mis au jour lors des fouilles de la mission karakalpak-australienne à Akchakhan-kala (occupé entre le $\mathrm{II}^{\mathrm{e}} \mathrm{s}$. av. et le $\mathrm{II}^{\mathrm{e}} \mathrm{s}$. de n.è.), un fragment de rhyton en ivoire et un moule en terre cuite en forme de tête de satyre destiné à décorer de la vaisselle en céramique. Il passe en revue les possibles analogies stylistiques et propose d'y voir une influence de la culture hellénistique d'Asie centrale en Chorasmie, où l'on cultivait la vigne et consommait du vin au moins dès le $\mathrm{V}^{\mathrm{e}} \mathrm{s}$. av. n.è. Alors que la Chorasmie n'a jamais fait partie du territoire hellénistique, l'auteur suggère que l'adoption de traits stylistiques fait partie d'un ensemble de mesures destinées à asseoir le prestige de la dynastie régnante.

\section{AUTEURS}

JOHANNA LHUILLIER

UMR 5133 CNRS-Université de Lyon 